\title{
Prevalence of mobility disabilities in nursing home residents and the association with age, $\mathrm{BMI}$, fall risk and social participation
}

\author{
Patrick Fehling, Theo Dassen \\ Institute of Health and Nursing Science of the Charité Universitätsmedizin Berlin, Berlin, Germany
}

Received: July 12, 2017

DOI: $10.5430 /$ jnep.v7n12p105

\author{
Accepted: July 31, 2017 \\ Online Published: August 14, 2017 \\ URL: https://doi.org/10.5430/jnep.v7n12p105
}

\begin{abstract}
Background and aim: Physical mobility is often described as a basic prerequisite for independence, self-determination, and social participation. Older people, particularly those in long-term care facilities, are more often affected by the loss of their mobility. However, the prevalence of the mobility disabilities of nursing home residents and their association with demographic and care-specific/medical factors have so far been studied less. This prevalence study should investigate a possible association of mobility disability with age, BMI, multimorbidity, fall risk, and social participation.

Methods: The prevalence study covered the data of residents in 30 German residential care facilities (RCFs). Trained staff nurses used a standardised instrument to collect data about the age, obesity, medical diagnoses, the fall risk, the level of mobility disability, and the need for supporting the social participation of the residents.

Results: The representative sample included 2,066 nursing home residents, of whom 81.5\% required support in their mobility. The level of a mobility disability or the need for a support in matters of mobility by others was not associated either with age, with the BMI, or with the fall risk of the participants. The groups with higher mobility disability included the more multimorbid participants with more difficult medical diagnoses, and these had a higher need for support in their social participation.

Conclusions: It may be that professional care must reflect the premature link between older and obese patients with mobility disability. In addition to nursing diagnoses, medical diagnoses should necessarily be integrated into the nursing assessment. The association between the level of mobility disability and the fall risk, which is often mentioned in the literature, should be critically reflected. Nursing home residents should be informed that there is a possible association between their mobility disability and their social participation.
\end{abstract}

Key Words: Mobility disability, Nursing home residents, Prevalence, Association, Fall risk, Social participation

\section{BACKGROUND}

Physical mobility is often described as a basic prerequisite for independence ${ }^{[1,2]}$ and self-determination, ${ }^{[3]}$ social participation, ${ }^{[4,5]}$ quality of life ${ }^{[6]}$ and subjective well-being. ${ }^{[7]}$ People of all ages in need of health care professionals mostly have mobility disabilities of varying degrees (ibid.). That impairments of mobility are multifactorial (ibid.) is certainly out of the question, but above all, the elderly, and especially those in long-term care facilities, are affected by the disability of their mobility ${ }^{[8]}$ This prevalence study was devoted to rarely scientifically researched residential care facilities (RCF) and determined the level of mobility disability of nursing home residents.

It has been reported that the age of care recipients affects their

*Correspondence: Patrick Fehling; Email: patrick.fehling@charite.de; Address: Caseler Str. 3, 13088 Berlin, Germany. 
level of mobility. ${ }^{[9,10]}$ Currently, $5 \%$ of the 70 to 75 -year-old German citizens need caring support, including mobility support, but $66 \%$ of the citizen older than 90 years are in need of that care support. ${ }^{[11]}$ It can, therefore, be assumed that, on the one hand, most German nursing home residents show disabilities in their mobility and, on the other hand, the older nursing home residents have more mobility disabilities than the younger ones.

Overweight and obesity present other challenging public health problems in industrialised countries that is also affecting the people in need of care. ${ }^{[12]}$ Overweight and obese residents have complex needs that complicate their care and increases the caregivers' workload. ${ }^{[13]}$ The mobilization of obese residents in RCFs is a challenge. ${ }^{[12]}$ Although RCFs are increasingly confronted with overweight residents, efforts to mobilize and use the resources needed are rarely investigated. ${ }^{[14]}$ However, it is conclusive to assume that obese residents are less mobile and need more support than lean residents. This relationship may be explained by a higher rate of multimorbidity in obese residents. The nursing sciences have thus far published little on the prevalence of multimorbidity in RCFs, i.e. the combination of several medical diagnoses in a person in need of care. This could be because nursing science currently defines its field of activity. ${ }^{[15]}$ Inevitably, it is distancing itself from an important, if not the most important reference discipline: the medical science. Correspondingly, nursing scientists demand professional caregivers to assess care recipients only from a nursing perspective and therefore self-reliant, and not from a medical perspective in general and with the use of medical diagnoses in particular. ${ }^{[16,17]}$ For a comprehensive nursing assessment, the medical diagnoses of those in need of care certainly play a significant role. ${ }^{[18,19]}$ It is, however, to be assumed that a higher number of medical diagnoses, i.e. multimorbidity, ${ }^{[20]}$ is associated with the level of mobility disability in nursing home residents. ${ }^{[21]}$

Preliminary results also indicate a relationship between mobility disability and the probability of a fall. ${ }^{[22-24]}$ This phenomenon is particularly often reported in RCFs. ${ }^{[25]}$ Nursing scientists have analyzed the severity of physical, psychologi$\mathrm{cal}$, and economic consequences of a fall of an older adult. ${ }^{[26]}$ Given the growing number of older adults living in nursing homes, which also have higher mobility disabilities, ${ }^{[27]}$ the problem of falls in RCFs could increase. It is, therefore, conclusive to assume that residents with a greater mobility disability also have a higher fall risk.

As mentioned above, the mobility disability of nursing home residents influences their social participation. It is assumed that social participation is a vital key to the active aging also to the elderly. ${ }^{[28]}$ Thus, the design and support of the social participation of care recipients are of crucial importance for professional care ${ }^{[29,30]}$ In the context of a new holistic assessment of all Germans in need of care since January 2017, the extent to which they are supported in their social participation is also seen as decisive for the right to financial and professional support. ${ }^{[28,31]}$ This paradigm shift in professional care not only benefits those in need of care, but the caregivers as well. The support of the social participation of care recipients by caregivers is now acknowledged and paid as nursing expenses, for instance, as support of mobilization. It is therefore also important to examine whether there is an association between the factors of mobility disability and the need for support in the social participation of people in need of care, as is more frequently indicated in the literature. Is it possible to quantify the fact that those in need of care who have a higher level of mobility disability also need more support in the context of their social participation?

\section{Hypotheses}

This prevalence study examined the following four hypotheses:

(1) Most nursing home residents need help with their mobility (Hypothesis 1)

(2) Older nursing home residents and those with a higher BMI or more difficult medical diagnoses are more dependent on the support by caregivers than residents who are younger, have a lower BMI or less medical diagnoses (Hypothesis 2).

(3) Nursing home residents with more need for support in their mobility have a higher fall risk than those who need less help (Hypothesis 3).

(4) Nursing home residents who are independent in their mobility also need less support in their social participation than those who are partially or completely dependent on the help of others (Hypothesis 4).

\section{METHOD}

\subsection{Design}

The data analysis is based on two cross-sectional prevalence studies from 2014 and 2015, carried out by the Institute of Health and Nursing Science of the Charité Universitätsmedizin Berlin in German hospitals and RCFs. The focus of this analysis was on the empirical data of the two prevalence studies collected in the German RCFs. Methods and procedures followed a standardized study protocol for conducting prevalence studies of care problems in Germany, which has now been used for several years. ${ }^{[32]}$

\subsection{Sample}

Residents of 14 (in 2014) and 16 (in 2015) RCFs participated voluntarily in these two prevalence studies. The response 
rate was between $30.3 \%$ and $100 \%$, an average of $87.1 \%$.

\subsection{Data collection}

As described by Heinze et al. ${ }^{[33]}$ and Lahmann et al. ${ }^{[34]}$ in more detail, professional caregivers in the participating RCFs were qualified for data collection by the scientists of the Institute of Health and Nursing Science of the Charite Universitätsmedizin Berlin. On the basis of standardized procedures $^{[35]}$ and comprehensive guidance documents, as well as close supervision by the Institute scientists, these caregivers carried out the data collection together with the participating nursing home residents. Data collection occurred within each facility on one single day during a specified week in 2014 and 2015, and upon their completion, the data collection forms were sent to the institute, where data were verified and analyzed. ${ }^{[32]}$

The participants had to be at least 18 years old and have given their informed consent. There were no further restrictions. The study protocol was approved by the Ethical Committee of the Berlin Medical Association.

\subsection{Measures}

This study analyzed the age, sex, obesity (quantified by the BMI), medical diagnoses, the fall risk, the level of mobility disability, and the need for support in the social participation of the nursing home residents who had participated. The participants could be assigned to seven possible medical diagnoses: Diabetes mellitus, stroke, dementia, cardiovascular, musculoskeletal, mental, or oncological diseases.

The fall risk of the participants could be classified from 1 (very low) to 10 (very high). The level of mobility disability and the social participation was quantified using the Care Dependency Scale (CDS). The CDS was developed in the Netherlands by Dijkstra et al. ${ }^{[36]}$ and includes various physical and psychosocial components, similar to the new appraisal assessment instrument launched by German insurance companies in 2017 to reclassify all care recipients. The CDS contains 15 items (e.g. Eating and Drinking, Mobility, Continence, Daily Activities, Recreational Activities, and Contact with Others) each with five criteria on a five-point Likert scale, ranging from completely caredependent to completely care-independent. ${ }^{[37]}$ The quality of the CDS is similar to that of the Barthel Index, an appropriate instrument for assessing changes in care recipients over time. ${ }^{[38]}$ Therefore, it is now used internationally ${ }^{[39]}$ and has been adapted accordingly. ${ }^{[40-42]}$ Since there is no clear definition of the social participation of residents, ${ }^{[43]}$ it was analogous to Gilmour's ${ }^{[44]}$ and described as daily physical activities, activities in contact with family or friendships, and recreational activities involving other people. Therefore, the synonyms in the CDS instrument, the items daily activities, recreational activities, and contact with others were used as a data basis for the quantification of the social participation of the participants. These three CDS items were divided dichotomously into "completely independent" and into the four criteria "completely dependent, almost dependent, partially dependent, almost independent", ${ }^{[35]}$ to compare the independent participants with those who were partially or completely dependent on the help of others.

\subsection{Data analysis}

The two data sets of the prevalence studies from 2014 und 2015 were merged and analysed using SPSS for Windows (IBM SPSS Statistics, Version 24) and Google Sheets. Firstly, the absolute and relative frequencies of the variables age, gender, BMI, medical diagnoses, fall risk, and the CDS items of the participants were calculated. The standard deviation $(\sigma)$ and $95 \%$ confidence interval $(95 \% \mathrm{CI})$ were calculated for the mean values of age, BMI, and fall risk. To associate these variables with the levels of mobility disability, the variables were calculated for each of the five criteria of the CDS item mobility.

\section{RESULTS}

\subsection{Description}

The demographic characteristics age, BMI, and gender of the 2,066 nursing home residents of the various German nursing homes who took part in this prevalence study are summarized in Tables 1 and 2. The average age of the participants was 80.95 years $(95 \% \mathrm{CI}=80.42-81.47$ years, $\sigma=12.15$ years $)$. For evaluating the external validity of the results and the conclusions of this study, the age distribution of the participants was carried out in 10-year increments (see Figure 1). The distribution of participants in the nine age cohorts shows that most of the nursing home residents $(84.8 \%)$ were between 70 and 99 years old. At $42.8 \%$, the age cohorts $80-89$ years dominated the other cohorts.

Table 1. Participants' characteristics

\begin{tabular}{llll}
\hline & & Age & BMI \\
\hline Mean & & 80.95 & 26.09 \\
95\% Confidence & Lower Bound & 80.42 & 25.85 \\
Interval for Mean & Upper Bound & 81.47 & 26.33 \\
Median & & 84.00 & 25.47 \\
Std. Deviation & & 12.147 & 5.485 \\
Minimum & 26 & 12 \\
Maximum & 105 & 61 \\
Range & & 79 & 49 \\
\hline
\end{tabular}


Table 2. Participants' characteristics

\begin{tabular}{llll}
\hline Gender & & Frequency & Valid Percent (\%) \\
\hline \multirow{3}{*}{ Valid } & Male & 571 & 28.9 \\
& Female & 1405 & 71.1 \\
& Total & 1976 & 100.0 \\
Missing & & 90 & \\
Total & & 2066 & \\
\hline
\end{tabular}

The average BMI was $26.09 \mathrm{~kg} / \mathrm{m}^{2}(95 \% \mathrm{CI}=25.85$ $26.33 \mathrm{~kg} / \mathrm{m}^{2}, \sigma=5.49 \mathrm{~kg} / \mathrm{m}^{2}$ ). According to the WHO classification, ${ }^{[45]}$ this corresponds to pre-obesity (25.0-30.0 $\mathrm{kg} / \mathrm{m}^{2}$ ).

The participants were assigned to the seven medical diagnoses as follows: Stroke $15.4 \%(\mathrm{n}=318)$, musculoskeletal diseases 46.9\% ( $\mathrm{n}=969)$, dementia 51.1\% ( $\mathrm{n}=1,056)$, mental diseases $24.5 \%(\mathrm{n}=507)$, cardio-vascular diseases $62.7 \%$ $(\mathrm{n}=1,296)$, diabetes mellitus $25.1 \%(\mathrm{n}=518)$ and oncological diseases $7.6 \%(n=158)$. Accumulated, most of the participants had two $(n=710)$, three $(n=583)$ medical diagnoses. A little less frequently, the participants had only one diagnosis $(n=416)$ or four or more diagnoses $(n=290)$.

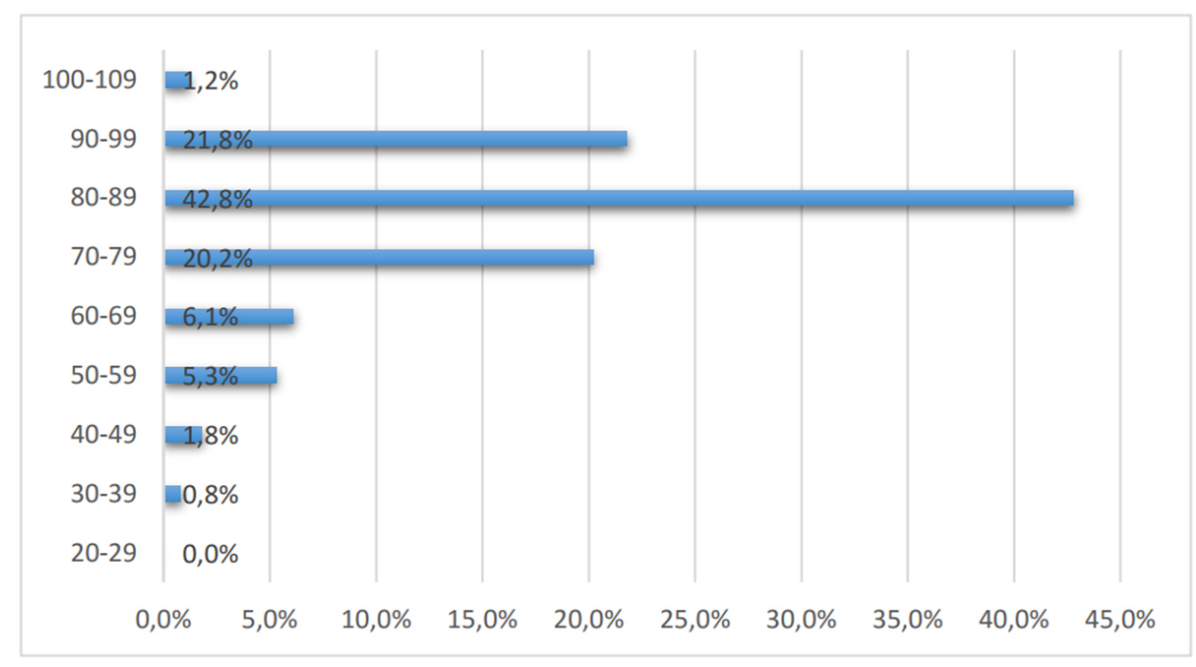

Figure 1. Age of the participants distributed in 10-year increments

In the CDS-Item Mobility, participants were classified into independent. The fairly homogeneous distribution within the five criteria between completely dependent and completely criteria is shown in Table 3 .

Table 3. Association of the Level of mobility disability with age, BMI, sum of medical diagnoses, and the fall risk of the participants

\begin{tabular}{|c|c|c|c|c|c|c|}
\hline \multicolumn{3}{|l|}{ Level of Mobility Disability } & \multirow{2}{*}{$\begin{array}{l}\text { Age } \\
\text { years }\end{array}$} & \multirow{2}{*}{$\frac{\text { BMI }}{\mathrm{kg} / \mathrm{m}^{2}}$} & \multirow{2}{*}{$\begin{array}{l}\begin{array}{l}\text { Sum of medical } \\
\text { diagnoses }\end{array} \\
n\end{array}$} & \multirow{2}{*}{$\begin{array}{l}\text { Fall risk } \\
\text { From } 1 \text { (very low) to } \\
10 \text { (very high) }\end{array}$} \\
\hline Kriteria & n & $\%$ & & & & \\
\hline completely dependent & 488 & $23.8 \%$ & 78.28 & 24.48 & 2.51 & 3.55 \\
\hline almost dependent & 318 & $15.5 \%$ & 82.19 & 26.30 & 2.55 & 4.50 \\
\hline partially dependent & 394 & $19.2 \%$ & 82.32 & 25.97 & 2.46 & 4.51 \\
\hline almost independent & 473 & $23.0 \%$ & 82.72 & 27.18 & 2.25 & 3.50 \\
\hline completely independent & 381 & $18.5 \%$ & 79.61 & 26.75 & 1.90 & 3.03 \\
\hline & $\Sigma=2054$ & $\Sigma=100 \%$ & $\varnothing=80.96$ & $\varnothing=26.09$ & $\varnothing=2.33$ & $\varnothing=3.78$ \\
\hline
\end{tabular}

The distribution of the fall risk from very low to very high is shown in Figure 2, including the continuously decreasing relative frequency of the participants with fall risk $(n=1,705)$ from $21.9 \%$ (FR 1) to $2.6 \%$ (FR 10). The mean estimated fall risk was 3.8 (95\% CI 3.7-3.9). 


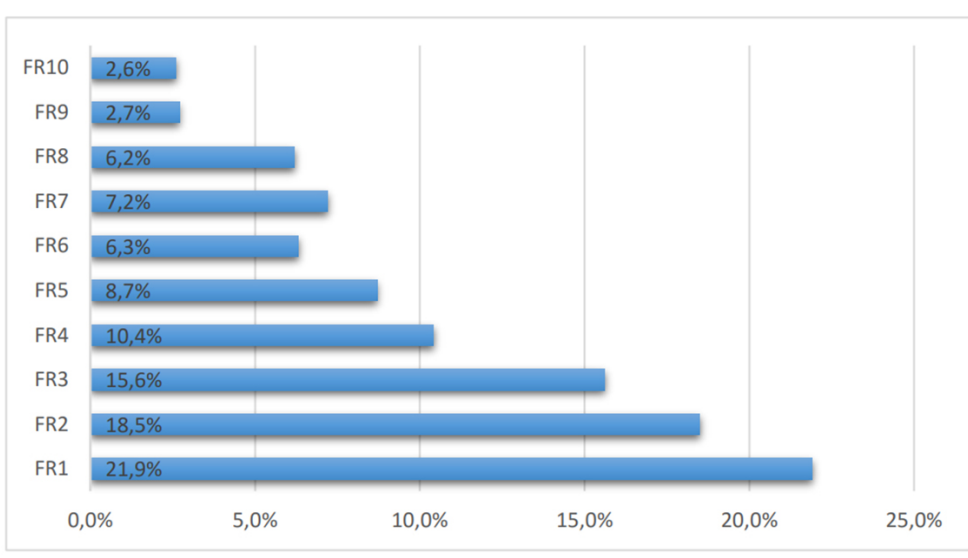

Figure 2. Distribution of the fall risk (FR) from very low (FR1) to very high (FR2)

\subsection{Associations}

To validate Hypothesis 2, the five levels of mobility disability of the CDS instrument were associated with age, BMI, and the sum of medical diagnoses. The result is shown in Table 3. The average age of the participants in the five levels of mobility disability was between 78.3 and 82.7 years, which is \pm 2.7 years around the average age of all participants. The BMI in the five levels varies by less than $\pm 1.6 \mathrm{~kg} / \mathrm{m}^{2}$ around the average BMI of all participants. Neither the mean values of the age nor the mean values of the BMI show significant increases or decreases over the five levels of mobility disabilities.

The sum of the medical diagnoses which the participants had rose only slightly but continuously from an average of 1.90 to 2.55 medical diagnoses (an exception is the group "completely dependent" with a slightly reduced diagnosis sum of 2.55).

The assignment of the level of mobility disability of the participants to their fall risk (Hypothesis 3 ) is also shown in Table 3. The average fall risk of the participants of the five levels of mobility disability varies significantly from 3.03 to 4.51, but a markedly increasing or decreasing trend is not apparent.

To finally validate the Hypothesis 4, the CDS item mobility was associated with the CDS items contact with others, daily activities, and recreational activities. In each level of mobility disability, the proportion of participants who were independent was calculated, as well as the proportion of participants who were dependent on the support of others. The result in Table 4 shows the high variance of the relative frequencies of the participants who needed help in the three CDS items and the significant increase, the more their mobility was disabled.

Table 4. Association of the level of mobility disabilities with contact with others, recreational activities, and daily activities

\begin{tabular}{|c|c|c|c|c|c|c|c|c|c|c|c|c|c|c|c|c|c|}
\hline \multirow{2}{*}{\multicolumn{3}{|c|}{ Level of Mobility Disability }} & \multicolumn{5}{|c|}{ Contact with Others } & \multicolumn{5}{|c|}{ Recreational Activities } & \multicolumn{5}{|c|}{ Daily Activities } \\
\hline & & & \multicolumn{2}{|c|}{$\begin{array}{l}\text { In need of } \\
\text { support }\end{array}$} & \multicolumn{2}{|c|}{$\begin{array}{l}\text { Completely } \\
\text { independent }\end{array}$} & \multirow[b]{2}{*}{ Sum } & \multicolumn{2}{|c|}{$\begin{array}{l}\text { In need of } \\
\text { support }\end{array}$} & \multicolumn{3}{|c|}{$\begin{array}{l}\text { Completely } \\
\text { independent }\end{array}$} & \multicolumn{2}{|c|}{$\begin{array}{l}\text { In need of } \\
\text { support }\end{array}$} & \multicolumn{2}{|c|}{$\begin{array}{l}\text { Completely } \\
\text { independent }\end{array}$} & \multirow[b]{2}{*}{ Sum } \\
\hline Criteria & $\mathbf{n}$ & $\%$ & $\mathbf{n}$ & $\%$ & $\mathbf{n}$ & $\%$ & & n & $\%$ & $\mathbf{n}$ & $\%$ & Sum & $\mathbf{n}$ & $\%$ & $\mathbf{n}$ & $\%$ & \\
\hline $\begin{array}{l}1 \text { completely } \\
\text { dependent }\end{array}$ & 488 & 23.8 & 470 & 96.3 & 18 & 3.7 & 488 & 474 & 98.1 & 9 & 1.9 & 483 & 473 & 98.3 & 8 & 1.7 & 481 \\
\hline $\begin{array}{l}2 \text { almost } \\
\text { dependent }\end{array}$ & 318 & 15.5 & 266 & 84.4 & 49 & 15.6 & 315 & 301 & 95.3 & 15 & 4.7 & 316 & 305 & 96. & 10 & 3.2 & 315 \\
\hline $\begin{array}{l}3 \text { partially } \\
\text { dependent }\end{array}$ & 394 & 19.2 & 297 & 75.4 & 97 & 24.6 & 394 & 345 & 88.5 & 45 & 11.5 & 390 & 361 & 91.6 & 33 & 8.4 & 394 \\
\hline $\begin{array}{l}4 \text { almost } \\
\text { independent }\end{array}$ & 473 & 23.0 & 279 & 59.0 & 194 & 41.0 & 473 & 355 & 75.1 & 118 & 24.9 & 473 & 354 & 75.0 & 118 & 25.0 & 472 \\
\hline \multirow[t]{3}{*}{$\begin{array}{l}5 \text { completely } \\
\text { independent }\end{array}$} & 381 & 18.5 & 115 & 30.5 & 262 & 69.5 & 377 & 215 & 56.4 & 166 & 43.6 & 381 & 206 & 54.4 & 173 & 45.6 & 379 \\
\hline & $\Sigma=$ & $\Sigma=$ & $\Sigma=$ & $\emptyset=$ & $\Sigma=$ & $\varnothing=$ & $\Sigma=$ & $\Sigma=$ & $\varnothing=$ & $\Sigma=$ & $\emptyset=$ & $\Sigma=$ & $\Sigma=$ & $\emptyset=$ & $\Sigma=$ & $\varnothing=$ & $\Sigma=$ \\
\hline & 2,054 & 100 & 1,427 & 69.7 & 620 & 30.3 & 2,047 & 1,690 & 82.7 & 353 & 17.3 & 2,043 & 1,699 & 83.2 & 342 & 16.8 & 2,041 \\
\hline
\end{tabular}

\section{Discussion}

\subsection{Description}

So far, there was hardly any current data on the number of medical diagnoses and the BMI of the residents of German
RCFs and their effects on mobility disability. ${ }^{[14]}$ The two following demographic characteristics of this sample verify that the results of this study are based on representative data. There were $28.9 \%$ male $(n=571)$ and $71.1 \%$ female $(n=$ $1,405)$ nursing home residents in the sample. This distribu- 
tion was roughly similar to the distribution in German RCFs in 2013, which had $73 \%$ female nursing home residents. ${ }^{[46]}$ The age cohort 80-89 years in this sample contained $42.8 \%$ of all participants, while in German nursing homes according to the Federal Statistical Office, the same age cohort had $43.8 \%$ of all residents. $22.9 \%(n=475)$ of the participants in this sample were older than 90 years, in German RCFs it was similar with $25 \%$ (ibid.). Thus, the demographic characteristics of the sample corresponds to those of the German nursing home residents, which underlines the external validity of the results and conclusions.

According to an initial research, there are neither studies for Germany nor international studies on the type and extent of medical diagnoses in nursing home residents. The current study quantified that most participants had cardiovascular diseases or dementia and not diabetes mellitus, cancer, or stroke. Most of the participants had two or three of the medical diagnoses recorded here, and were therefore multimorbid. ${ }^{[21]}$ With regard to the disability of the mobility of the participants, the medical diagnosis is not insignificant as a possible causative parameter. Based on the data presented in this study, it will be possible in future evaluations to correlate the quality of mobility disability with the individual medical diagnoses of the participants using a multinomial logistic regression.

\section{Hypothesis 1}

From Table 3, it is clear that the majority of participants needed help with their mobility.

While $18.5 \%(n=381)$ of the participants were completely independent of mobilisation assistance from others, $23.0 \%$ were almost independent, $19.2 \%$ partly dependent, $15.5 \%$ nearly dependent, and $23.8 \%$ completely dependent, a total of $81.5 \%(n=1,673)$. Thus, qualitative statements such as "the majority of nursing home residents have a mobility disability" ${ }^{[8]}$ could be quantified, and the estimate of Slaughter et al. ${ }^{[47]}$ that $90 \%$ of the residents have mobility disabilities can now be specified. The current study also quantifies the high demand for support for nursing home residents, which is usually provided by other people and in RCFs, mainly by caregivers. This result cannot show the degree or extent of the burden on caregivers, but on the one hand, it underscores the extent of the objective and thus, the presumably subjectively perceived dependency of the residents on caregivers affecting their self-determination. ${ }^{[3,48]}$ On the other hand, the demands placed on the professional caregivers can be deduced by this result, which are demands that the professional caregivers probably cannot fulfill because they seem overloaded $^{[49]}$ and because a global nursing shortage ${ }^{[50]}$ could restrict the resources to mobilize nursing home residents.

\subsection{Association}

Hypothesis 2

Unexpectedly, the group of participants with a higher level of mobility disability had neither a higher average BMI nor a higher average age than the participants in the more independent groups. Conversely, it can be excluded in this sample that younger or slimmer nursing home residents rarely had mobility disabilities. On the contrary, the participants, who were completely dependent on other people in their mobility, had an average BMI of $24.5 \mathrm{~kg} / \mathrm{m}^{2}$, which is classified as normal weight according to the $\mathrm{WHO},{ }^{[45]}$ which is significantly lower than the participants in other groups. This association should be investigated further in future studies. Carrara et al. ${ }^{[51]}$ describe in an analogy that they were not able to detect a significant difference in the workload of caregivers in dealing with obese versus non-obese care recipients. Tannen et al. ${ }^{[52]}$ also found that residents with a higher degree of care dependency were more likely to have a BMI of less than $20 \mathrm{~kg} / \mathrm{m}^{2}$.

However, the level of mobility disability and the number of medical diagnoses seem to correlate. In any case, for this sample, the groups with the higher mobility disability (except the group of completely dependent participants) also have more medical diagnoses. With regard to the above-described orientation of nursing science towards their own profession, it must be said that by the results of this study, medical diagnoses should necessarily be integrated into the assessment of the patient. ${ }^{[19,53]}$

\section{Hypothesis 3}

The results of this study clearly show that participants who were more disabled in their mobility were not at higher fall risk or that the independent participants had no lower fall risk. Thus, Hypothesis 3 must be rejected. A clear link between mobility disability and the fall risk, which is often mentioned in the literature ${ }^{[54-56]}$ must be critically reflected because of the current study.

It is also noticeable that the fall risk is slightly lower in the first (completely dependent) and last (completely independent) groups of the mobility-disabled than in the groups with the criteria almost dependent, partly dependent, and almost independent. A future study should examine what caused this distribution.

\section{Hypothesis 4}

This hypothesis must clearly be accepted. Table 4 clearly shows an association between the level of mobility disability of the participants and their need for support in contact with others, daily activities, and recreational activities. Although no causal correlation can be derived, the following relationship seems very likely: the more the mobility of the residents 
is disabled, the more they depend on the help of others to maintain contact with their environment, to shape their daily lives, and to pursue meaningful leisure activities. The scientific literature confirms that limitations in mobility may lead to restricted social participation. ${ }^{[28,57,58]}$ As a result, professional caregivers should be aware that mobility-disabled residents are likely to need elaborate help with their social participation. Also, the nursing home residents should be educated about this association to be prepared for a possible connection between their mobility disability and their need for support in their social participation.

\section{Conclusion}

Two hypotheses in this study have proved true, one had to be rejected, and one was only partially accepted. Based on the data of the current, representative prevalence study, the level of a mobility disability or the need for support in matters of mobility by others was not associated with the age or with the BMI of the residents involved. It can, therefore, be excluded for the context of RCF that older or obese people need more support in their mobility than younger or slimmer ones.

It is possible that the professional care prejudices against elderly and obese people need to be reflected upon, prejudices that have solidified in society. ${ }^{[59,60]}$ As in the UK, guidelines for the non-judgmental treatment of elderly or obese residents should also be implemented in German professional care training. ${ }^{[61]}$

However, the association between the number of medical diagnoses and thus the multimorbidity and the level of mobility disability appears to be certain.

For this sample, the majority of nursing home residents who took part $(81.5 \%)$ needed support in their mobility. Only $18.5 \%$ of the participants were completely independent, which is a result that depicts the dependency ratio of most residents and the caregiver's support performance.
There was also no clear tendency in the association between the fall risk and the mobility disability of the participants. It can be ruled out that residents who are more disabled in their mobility have a higher fall risk. This may lead to a critical discourse within nursing sciences as well as a new assessment of the care recipients in RCFs.

Finally, the association between the level of mobility disability and the need for partial or comprehensive support for the social participation of nursing home residents seems obvious. Clarification of a possible causal correlation was not provided for in this study. However, by this prevalence study, a correlation should be assumed and communicated to those involved in the care process.

\section{Limitations}

Although the sample consisted of residents of different RCFs in Germany and their demographic characteristics such as age and gender were similar to German nursing home residents, no comprehensive external validity can be assumed, if only because no random procedure had been used.

The nurses who carried out the surveys used standardized procedures and were trained and supported by the research team of the science institute. Nevertheless, it cannot be ruled out that nursing staff assessed the participants only on the basis of their own documentation or by that their subjective perception influenced their data collection.

Isolating some of the $15 \mathrm{CDS}$ items and assigned the participants to mobility disability groups and age cohorts has simplified the results and thus, the conclusions.

\section{ACKNOWLEDGEMENTS}

We thank Steven R. Conlon for his technical assistance with the line art.

\section{CONFlicts of InTEREST Disclosure}

The authors declare that they have no competing interests.

\section{REFERENCES}

[1] Bourret EM, Bernick LG, Cott CA, et al. The meaning of mobility for residents and staff in long-term care facilities 2002. Available from: https://www.ncbi.nlm.nih.gov/pubmed/118721 03 (accessed June 14, 2017).

[2] Lenardt MH, de Sousa JAV, Grden CR, et al. Gait speed and cognitive score in elderly users of the primary care service 2015. Available from: https://www.ncbi.nlm.nih.gov/pubmed/266764 41 (accessed January 2, 2017).

[3] Schenk L, Meyer R, Behr A, et al. Quality of life in nursing homes: Results of a qualitative resident survey. 2013. Available from: https://www.ncbi.nlm.nih.gov/pubmed/235954

Published by Sciedu Press
11 (accessed June 12, 2017).

[4] Souza AMR, Fillenbaum GG, Blay SL. Prevalence and Correlates of Physical Inactivity among Older Adults in Rio Grande do Sul, Brazil. PLoS One. 2015; 10: e0117060. PMid:25700161 https://doi.org/10.1371/journal.pone. 0117060

[5] Lowndes R, Angus J, Peter E. Diabetes Care and Mental Illness: Constraining Elements to Physical Activity and Social Participation in a Residential Care Facility. Canadian Journal of Diabetes. 2013; 37: 220-5. PMid:24070884 https://doi.org/10.1016/j.jcjd .2013 .03 .361

[6] Ilgin D, Ozalevli S, Kilinc O, et al. Gait speed as a functional capacity indicator in patients with chronic obstructive pulmonary dis- 
ease. Ann Thorac Med. 2011; 6: 141-6. PMid:21760846 https: //doi.org/10.4103/1817-1737.82448

[7] DNQP. Expertenstandard nach § 113a SGB XI Erhaltung und Förderung der Mobilität in der Pflege - Abschlussbericht 2014. Available from: https://www.gkv-spitzenverband.de/media/d okumente/pflegeversicherung/qualitaet_in_der_pfleg e/expertenstandard/Pflege_Expertenstandard_Mobil itaet_Abschlussbericht_14-07-14_finaleVersion.pdf (accessed March 14, 2017).

[8] Wingenfeld K, Büscher A. Instrumente zur Einschätzung von Pflegebedürftigkeit In: Reuschenbach, B./Mahler, C. (Hg.): Pflegebezogene Assessmentinstrumente. Bern: Huber; 2011.

[9] Shafie S, Shahwan S, Abdin E, et al. The correlates of slow gait and its relation with social network among older adults in Singapore. Aging Ment Health. 2016; 1-6. PMid:27433876 https: //doi.org/10.1080/13607863.2016.1202893

[10] Rubenstein LZ. Falls in older people: epidemiology, risk factors and strategies for prevention. Age Ageing. 2006; 35: ii37-41 PMid:16926202 https://doi.org/10.1093/ageing/af1084

[11] DESTATIS. Pflegestatistik 201-Pflege im Rahmen der Pflegeversicherung. 2017. Available from: https: //www.destatis.de/DE/Publikationen/Thematisch/ Gesundheit/Pflege/PflegeDeutschlandergebnisse 52240 01159004.pdf?_-_blob=publicationFile (accessed June 20, 2017).

[12] Winfield RD. Caring for the critically ill obese patient: challenges and opportunities 2014. Available from: https://www.ncbi.nlm .nih.gov/pubmed/25319015 (accessed March 9, 2017)

[13] Dambaugh LA, Ecklund MM. Progressive Care of Obese Patients. Crit Care Nurse. 2016; 36: 58-63. PMid:27481802 https://doi. org/10.4037/ccn2016510

[14] Apelt G, Ellert S, Kuhlmey A, et al. [Temporal and structural differences in the care of obese and non-obese people in nursing homes] 2012. Available from: https://www.ncbi.nlm.nih.gov/pubme d/22811294 (accessed March 9, 2017).

[15] Hülsken-Giesler M. Pflege und Technik - Annäherung an ein spannungsreiches Verhältnis Zum gegenwärtigen Stand der internationalen Diskussion. 2007. Available from: http://econtent.hog refe.com/doi/pdf/10.1024/1012-5302.20.2.103 (accessed February 21, 2017).

[16] Stefan H, Schalek K. POP $®$ - PraxisOrientierte Pflegediagnostik: Argumente für ein neues Klassifikationssystem in der Pflege. ProCare. 2009; 14: 26-9. https://doi.org/10.1007/s00735-009 -0173-6

[17] Ralph SS, Taylor CM. Nursing Diagnosis Reference Manual. Lippincott Williams \& Wilkins; 2005.

[18] Rössler W. Psychiatrische Rehabilitation: Unter Mitarbeit von Ch. Lauber. Springer-Verlag; 2013.

[19] Doenges ME, Moorhouse MF. Application of Nursing Process and Nursing Diagnosis: An Interactive Text for Diagnostic Reasoning. F.A. Davis; 2012.

[20] Panagioti M, Stokes J, Esmail A, et al. Multimorbidity and Patient Safety Incidents in Primary Care: A Systematic Review and Meta-Analysis. PLoS One. 2015; 10: e0135947. PMid:26317435 https://doi.org/10.1371/journal . pone. 0135947

[21] Ryan A, Wallace E, O'Hara P, et al. Multimorbidity and functional decline in community-dwelling adults: a systematic review. Health Qual Life Outcomes. 2015; 13: 168. PMid:26467295 https: //doi.org/10.1186/s12955-015-0355-9

[22] Phillips LJ, DeRoche CB, Rantz M, et al. Using Embedded Sensors in Independent Living to Predict Gait Changes and Falls. West J Nurs Res. 2016. https://doi.org/10.1177/0193945916662027
[23] McGough EL, Logsdon RG, Kelly VE, et al. Functional mobility limitations and falls in assisted living residents with dementia: physical performance assessment and quantitative gait analysis. J Geriatr Phys Ther. 2013; 36: 78-86. PMid:22976811 https: //doi.org/10.1519/JPT.0b013e318268de7f

[24] Schwesig R, Fischer D, Lauenroth A, et al. Can falls be predicted with gait analytical and posturographic measurement systems? A prospective follow-up study in a nursing home population. Clin Rehabil. 2012; 27: 183-90. PMid:22843355 https://doi .org/10.1 177/0269215512452880

[25] Rapp K, Becker C, Cameron ID, et al. Epidemiology of falls in residential aged care: analysis of more than 70,000 falls from residents of Bavarian nursing homes. J Am Med Dir Assoc. 2012; 13: 187.e1-6. PMid:21816682 https://doi.org/10.1016/j. jamda. 2011.0 6.011

[26] Ambrose AF, Paul G, Hausdorff JM. Risk factors for falls among older adults: A review of the literature. Maturitas. 2013; 75: 51-61. PMid:23523272 https://doi.org/10.1016/j.maturitas. 20 13.02.009

[27] König HH, Bernert S, Angermeyer MC. [Health Status of the German population: results of a representative survey using the EuroQol questionnaire]. Gesundheitswesen. 2005; 67: 173-82. PMid:15789280 https://doi.org/10.1055/s-2005-857991

[28] Tomioka K, Kurumatani N, Hosoi H. Age and gender differences in the association between social participation and instrumental activities of daily living among community-dwelling elderly. BMC Geriatr. 2017; 17: 99. PMid:28454521 https://doi.org/10.1186/s128 77-017-0491-7

[29] Hand C, McColl MA, Birtwhistle R, et al. Social isolation in older adults who are frequent users of primary care services. Can Fam Physician. 2014; 60: e322-e324.

[30] Top M, Dikmetaş E. Quality of life and attitudes to ageing in Turkish older adults at old people's homes. Health Expect. 2015; 18: 288-300. PMid:23240580 Available from: https://doi.org/10.1111/he $\mathrm{x} .12032$

[31] MDS. Richtlinien des GKV-Spitzenverbandes zur Feststellung der Pflegebedürftigkeit nach dem XI. Buch des Sozialgesetzbuches. Medizinischer Dienst Des Spitzenverbandes Bund Der Krankenkassen eV 2016. Available from: https: //www.mds-ev.de/fileadmin/dokumente/Publikationen /SPV/Begutachtungsgrundlagen/BRi_Pflege_ab_2017.pdf (accessed January 6, 2017).

[32] Kottner J, Dassen T, Lahmann N. Prevalence of deep tissue injuries in hospitals and nursing homes: two cross-sectional studies. Int J Nurs Stud. 2010; 47: 665-70. PMid:19962700 https: //doi.org/10.1016/j.ijnurstu.2009.11.003

[33] Heinze C, Halfens RJ, Dassen T. Falls in German inpatients and residents over 65 years of age. J Clin Nurs. 2007; 16: 495-501. PMid:17335525 https://doi.org/10.1111/j.1365-2702.20 06.01578. $\mathrm{x}$

[34] Lahmann NA, Halfens RJ, Dassen T. Pressure ulcers in German nursing homes and acute care hospitals: prevalence, frequency, and ulcer characteristics. Ostomy Wound Manage. 2006; 52: 20-33. PMid: 16464992

[35] Mertens EI, Halfens RJG, Dassen T. Using the Care Dependency Scale for fall risk screening. J Adv Nurs. 2007; 58: 594-601. PMid:17484744 https://doi.org/10.1111/j.1365-2648.20 07.04265. $\mathrm{x}$

[36] Dijkstra A. Care Dependency: An Assessment Instrument for Use in Long-term Care Facilities. 1998.

[37] Lohrmann C, Dijkstra A, Dassen T. The Care Dependency Scale: an assessment instrument for elderly patients in German hospitals. 
Geriatr Nurs. 2003; 24: 40-3. PMid:12598866 https://doi.org/ $10.1067 / \mathrm{mgn} .2003 .8$

[38] Eichhorn-Kissel J, Dassen T, Lohrmann C. Comparison of the responsiveness of the Care Dependency Scale for rehabilitation and the Barthel Index. Clin Rehabil. 2011; 25: 760-7. PMid:21402648 https://doi.org/10.1177/0269215510397558

[39] Dijkstra A, Hakverdioğlu G, Muszalik M, et al. Health related quality of life and care dependency among elderly hospital patients: an international comparison. Tohoku J Exp Med. 2015; 235: 193-200. PMid:25757561 https://doi.org/10.1620/tjem.235.193

[40] Zürcher SJ, Vangelooven C, Borter N, et al. Psychometric testing of the Italian and French versions of the Care Dependency Scale. J Adv Nurs. 2016; 72: 3207-15. PMid:27434620 https: //doi.org/10.1111/jan.13077

[41] Boggatz T, Farid T, Mohammedin A, et al. Psychometric properties of the extended Care Dependency Scale for older persons in Egypt. J Clin Nurs. 2009; 18: 3280-9. PMid:19930086 https: //doi.org/10.1111/j.1365-2702.2009.02946.x

[42] Rajabi G, Namadmalan M, Dijkstra A, et al. Psychometric Properties of the Persian Version of Care Dependency Scale in Nursing Homes. Rehabil Nurs. 2016. https ://doi.org/10.1002/rnj . 270

[43] Piškur B, Daniëls R, Jongmans MJ, et al. Participation and social participation: are they distinct concepts? Clin Rehabil. 2014; 28 : 211-20. PMid:23988324 https://doi.org/10.1177/02692155 13499029

[44] Gilmour H. Social participation and the health and well-being of Canadian seniors. Health Rep. 2012; 23: 23-32. PMid:23356042

[45] WHO. BMI classification. 2006. Available from: http://apps.w ho.int/bmi/index.jsp?introPage=intro_3.html (accessed March 13, 2017).

[46] DESTATIS. Pflegestatistik 2013 Pflege im Rahmen der Pflegeversicherung Deutschlandergebnisse. 2015. Available from: https://www.destatis.de/DE/Publikationen/Thematisc h/Gesundheit/Pflege/PflegeDeutschlandergebnisse522 4001139004.pdf?_-_blob=publicationFile (accessed March 9, 2017).

[47] Susan E, Slaughter CAE. Optimizing the mobility of residents with dementia: a pilot study promoting health care aide uptake of a simple mobility innovation in diverse nursing home settings. BMC Geriatr. 2013; 13: 110. PMid:24138586 https://doi.org/10.1186/14 71-2318-13-110

[48] Taylor J, Sims J, Haines TP. "I accept it [staff assistance]; no choice": an ethnographic study of residents' attitudes towards mobility within nursing homes. Int J Older People Nurs. 2013; 9: 258-68. PMid:23617552 https://doi.org/10.1111/opn.12029

[49] Lim J, Bogossian F, Ahern K. Stress and coping in Australian nurses: a systematic review. Int Nurs Rev. 2010; 57: 22-31. PMid:20487471 https://doi.org/10.1111/j.1466-7657.2009.00765.x
[50] Oulton JA. The Global Nursing Shortage: An Overview of Issues and Actions. 2006. Available from: http://journals. sagepub .com/doi/pdf/10.1177/1527154406293968 (accessed March 9, 2017).

[51] Carrara FS, Zanei SS, Cremasco MF, et al. Outcomes and nursing workload related to obese patients in the intensive care unit 2016 Available from: https://www.ncbi.nlm.nih.gov/pubmed/26 818706 (accessed March 9, 2017).

[52] Tannen A, Schütz T, Smoliner C, et al. Care problems and nursing interventions related to oral intake in German nursing homes and hospitals: a descriptive multicentre study. 2012. Available from: https: //www.ncbi.nlm.nih.gov/pubmed/22015166 (accessed March 9, 2017).

[53] Rössler W. Psychiatrische Rehabilitation: Unter Mitarbeit von Ch. Lauber. Springer-Verlag; 2013.

[54] Kröpelin TF, Neyens JCL, Halfens RJG, et al. Fall determinants in older long-term care residents with dementia: a systematic review. Int Psychogeriatr. 2013; 25: 549-63. PMid:23253253 https : //doi.org/10.1017/S1041610212001937

[55] Deandrea S, Bravi F, Turati F, et al. Risk factors for falls in older people in nursing homes and hospitals. A systematic review and metaanalysis. Arch Gerontol Geriatr. 2013; 56: 407-15. PMid:23294998 https://doi.org/10.1016/j.archger.2012.12.006

[56] Kosse NM, de Groot MH, Vuillerme N, et al. Factors related to the high fall rate in long-term care residents with dementia. Int Psychogeriatr. 2015; 27: 803-14. PMid:25465203 https ://doi.org/ 10.1017/S104161021400249X

[57] Saal S, Beutner K, Bogunski J, et al. Interventions for the prevention and treatment of disability due to acquired joint contractures in older people: a systematic review. Age Ageing. 2017; 1-10. https://doi.org/10.1093/ageing/afx026

[58] Avlund K, Vass M, Hendriksen C. Onset of mobility disability among community-dwelling old men and women. The role of tiredness in daily activities. Age Ageing. 2003; 32: 579-84. PMid:14599997 https://doi.org/10.1093/ageing/afg101

[59] Ilmarinen J. Towards a Longer Worklife! Ageing and the Quality of Worklife in the European Union. 2006.

[60] Kessler EM, Rakoczy K, Staudinger UM. The portrayal of older people in prime time television series: the match with gerontological evidence. Ageing Soc. 2004; 24: 531-52. https ://doi .org/10.1 017/S0144686X04002338

[61] Nicholls W, Pilsbury L, Blake M, et al. The attitudes of student nurses towards obese patients: A questionnaire study exploring the association between perceived causal factors and advice giving. 2016. Available from: https://www.ncbi.nlm.nih.gov/pubmed/26 608388 (accessed March 9, 2017). 